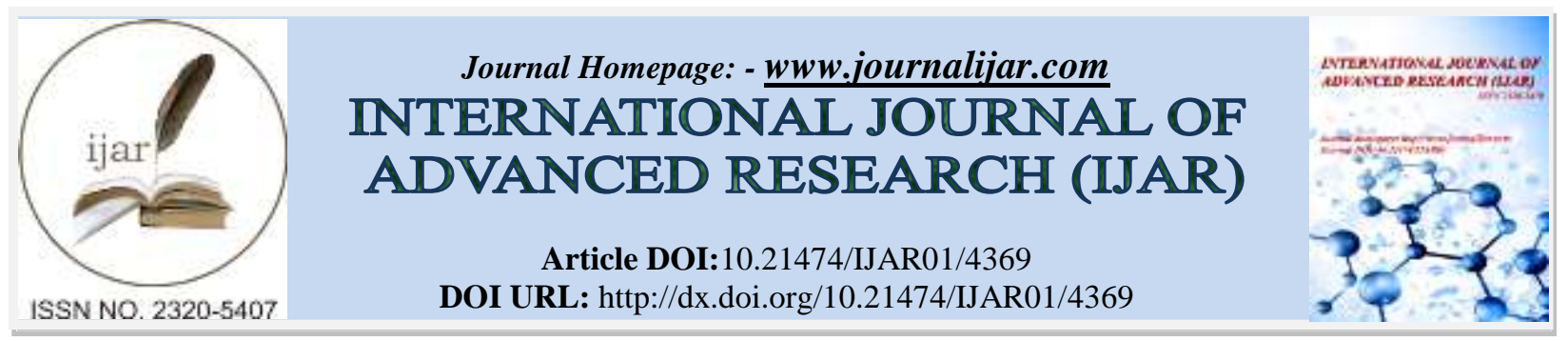

RESEARCH ARTICLE

\title{
HISTOMORPHOLOGICAL SPECTRUM OF UTERINE LEIOMYOMA VARIANTS- ONE YEAR RETROSPECTIVE STUDY IN A TERITARY CARE CENTRE.
}

\author{
Dr.Kokila $\mathrm{K}^{\mathbf{1}}$ and Dr.Rajavelu Indira ${ }^{2}$. \\ 1. Post Graduate, Department Of Pathology, Madras Medical College. \\ 2. Professor Of Pathology,Institute Of Social Obstetrics And Kasturba Gandhi Hospital For Women And Children.
}

\section{Manuscript Info}

…………............

Manuscript History

Received: 26 March 2017

Final Accepted: 28 April 2017

Published: May 2017

Key words:-

Hysterectomy, myomectomy, leiomyoma, cellular leiomyoma, atypical

/ symplastic leiomyoma, fatty

degeneration, myxoid degeneration, neurilemmoma like variant.

\section{Abstract}

Background:Benign leiomyomas were the most common pelvic tumor in $\operatorname{women}_{(1,2,3)}$. Most myometrial tumors continue to be a major cause of morbidity and leading indication for hysterectomy in premenopausal women. And some of the leiomyoma variants,such as mitotically active leiomyoma, symplastic leiomyoma may simulate leiomyosarcoma or other malignant tumors as these tumors carry better prognosis and require detailed morphological study.

In this study, we ascertained the frequency with which these variants were diagnosed and the difficulties that were encountered during the diagnosis.

Materials and methods: A retrospective analysis of hysterectomy and myomectomy specimen that were received in our department, Institute of Social Obstetrics and Kasturba Gandhi Hospital for women and children, from April 2016 to April 2017 was performed. The details regarding patient age, clinical presentation were collected from the medical records.

Results:During our study period, we received 1879 hysterectomy specimens and 664 specimens were found to have fibroid. We also received 29 myomectomy specimen and all these specimens were subjected for routine histopathological examination. Typical leiomyomas constituted to $88.6 \%$ and other variants like mitotically active leiomyoma, symplastic leiomyoma, cellular leiomyoma, neurilemmoma like variant, fatty degeneration, hyaline degeneration, calicification and hydropic degeneration constituted $11.4 \%$.

Conclusion:Variants of leiomyoma were relatively less, but it is important to differentiate them from malignant myometrial neoplasms, as they have good prognosis. Tumor size, cytological and nuclear atypia, mitosis and coagulative necrosis were the most important histological features for differentiation.

Copy Right, IJAR, 2016,. All rights reserved.

\section{Background:-}

Smooth muscle tumors were the most frequent mesenchymal tumors of the uterus.(4) In most instances, the clinical behavior of uterine smooth muscle neoplasms could be reliably predicted by their conventional macroscopic and microscopic features. Patterns of growth, histological appearance, associations with vessels and degenerative 
changes provide the basis for the classification of most benign smooth muscle tumors of uterus.(5) However diagnostic dilemmas were encountered with leiomyoma variants because of their wide spectrum of gross and microscopic appearances often causing concern for malignancy. Thus, a correct classification was important as currently prognosis of its malignant counterpart, leiomyosarcoma, is dismal even when confined to the uterus at time of diagnosis.

\section{Objective:-}

The purpose of this study was to evaluate the histomorphological features of uterine leiomyoma variants from hysterectomy and myomectomy specimens.

\section{Materials and Methods:-}

In this study, we performed retrospective analysis of hysterectomy and myomectomy specimen from April 2016 to April 2017 in Institute of Social Obstetrics and Kasturba Gandhi Hospital for women and children and details regarding patient age,clinical presentation were collected.

A detailed macroscopic examination, including size, appearance and external surface were noted. The specimens were allowed to fix in $10 \%$ neutral buffered formalin for 24 to 48 hours. Multiple parallel sections were made and their cut surface was examined. The tissue bits from representative areas were taken for histopathological examination. Multiple sections of five microns thickness were cut and routinely stained with hematoxylin and eosin.

\section{Results:-}

We received 3319 specimens, among which 1879 were hysterectomy specimen done for varying indications and 29 were myomectomy specimen (including 4 cases of pregnancy associated fibroid).

Among 1879 hysterectomy specimen, 664 specimens were found to have fibroid and most of them were intramural in location and few located subserosally. Most fibroids were diagnosed clinically and some were incidental findings. Patients who underwent myomectomy (29 specimen) were in their reproductive age and found to have fundal fibroid, thus hysterectomy was deferred.

Most patients were in the premenopausal age group and had varied clinical presentation ranging from menorrhagia, mass abdomen,pain abdomen and dysmenorrhea. Patients with fundal fibroid presented with primary infertility, recurrent abortions and 4 cases of fibroid complicating pregnancy were noted.

Table 1:- Clinical presentation of the patients

\begin{tabular}{|c|c|c|}
\hline Clinical presentation & Number of women & Percentage of women \\
\hline Menorrhagia & 293 & $42.27 \%$ \\
\hline Mass abdomen & 89 & $12.84 \%$ \\
\hline Pain abdomen & 52 & $7.50 \%$ \\
\hline Dysmenorrhea & 41 & $5.91 \%$ \\
\hline Primary infertility & 2 & $0.33 \%$ \\
\hline Recurrent abortion & 3 & $0.43 \%$ \\
\hline Pregnancy associated & 4 & $0.57 \%$ \\
\hline Asymptomatic/incidental & 209 & $30.15 \%$ \\
\hline
\end{tabular}

Table 2:- Histomorphological variants of leiomyoma.

\begin{tabular}{|c|c|c|}
\hline Variant of leiomyoma & Number of cases & Percentage \\
\hline Typical leiomyoma & 614 & $88.6 \%$ \\
\hline Mitotically active & 3 & $0.43 \%$ \\
\hline Hydropic change & 1 & $0.14 \%$ \\
\hline Fatty degeneration & 9 & $6.29 \%$ \\
\hline Hyaline degeneration & 44 & $1.73 \%$ \\
\hline Calcific degeneration & 12 & $0.28 \%$ \\
\hline Symplastic leiomyoma & 2 & $0.43 \%$ \\
\hline Cellular leiomyoma & 3 & $0.14 \%$ \\
\hline Neurilemmoma like & 1 & \\
\hline
\end{tabular}




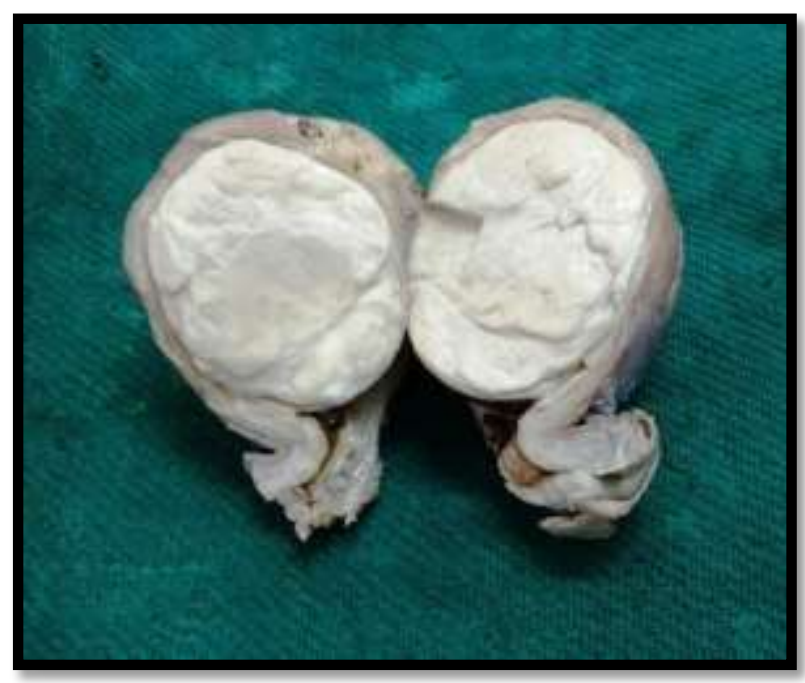

Fig 1:- Gross image of symplastic leiomyoma showing well circumscribed mass which was grey white,firm without areas of necrosis and hemorrhage.

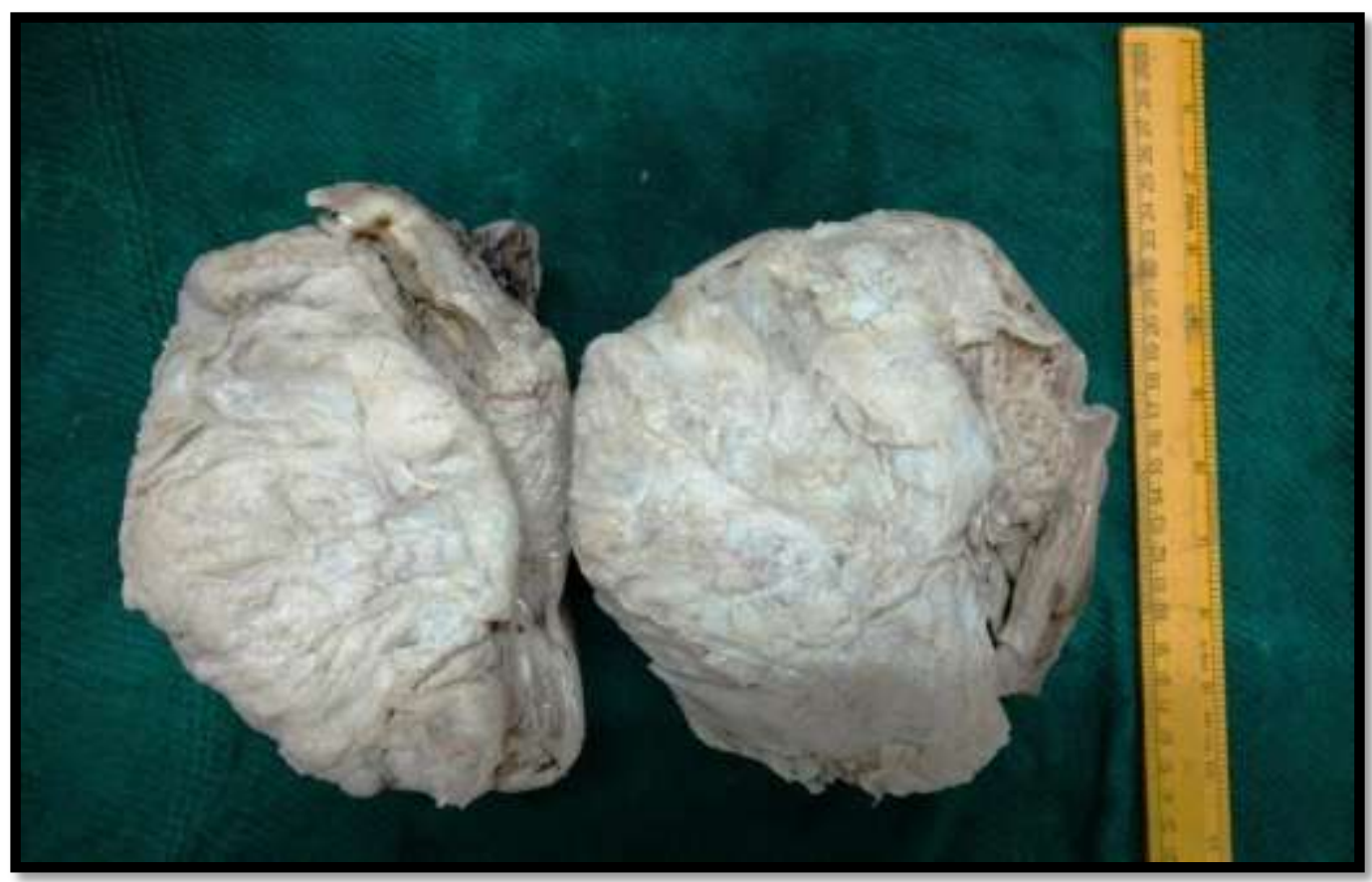

Fig 2:- Gross image of leiomyoma with myxoid areas. 


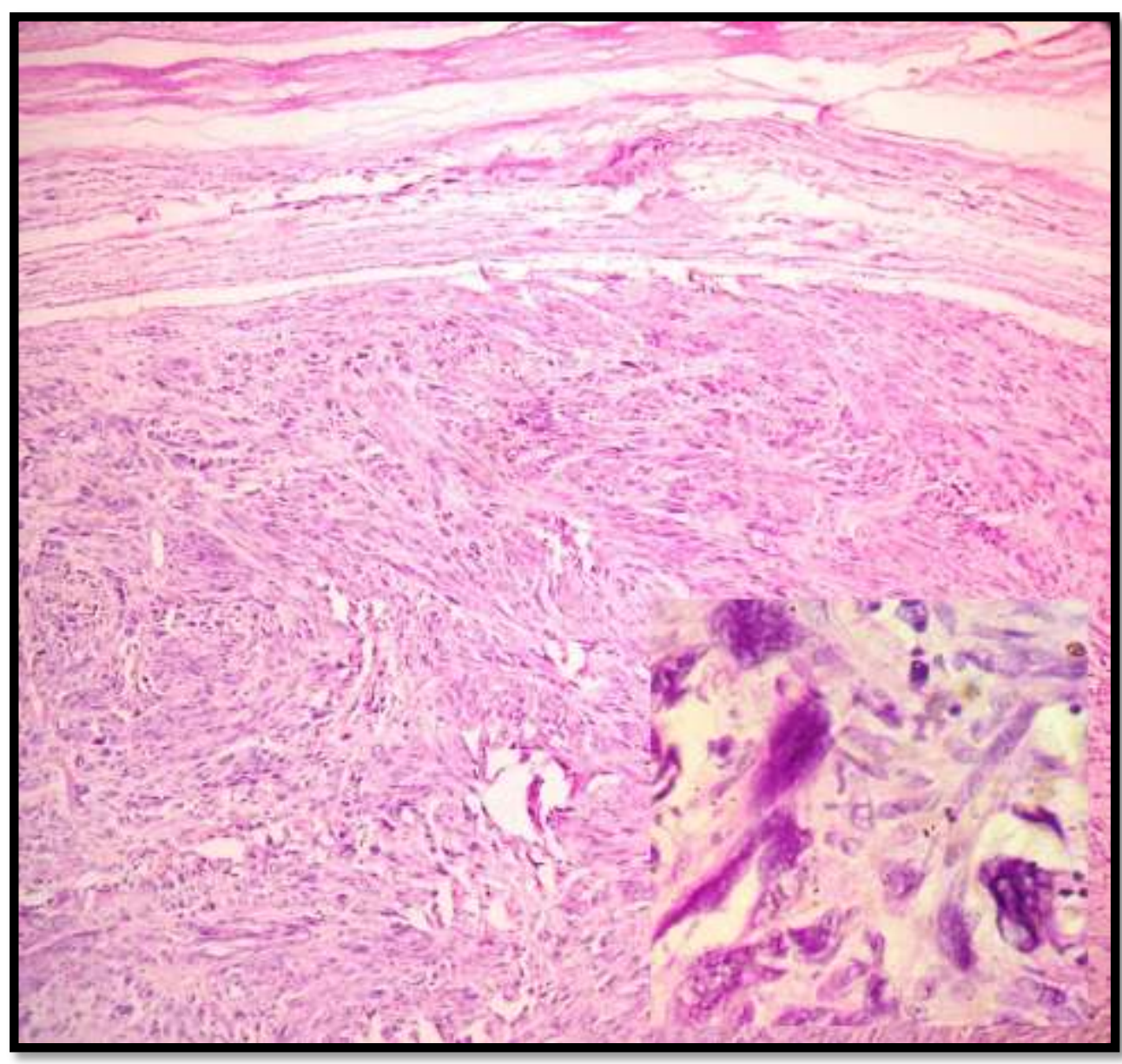

Fig3:- Symplastic leiomyoma-Scanner view (40X) showing well circumscribed neoplasm arranged in fascicles \& bundles.Inset showing pleomorphic bizarre hyperchromatic nuclei. 


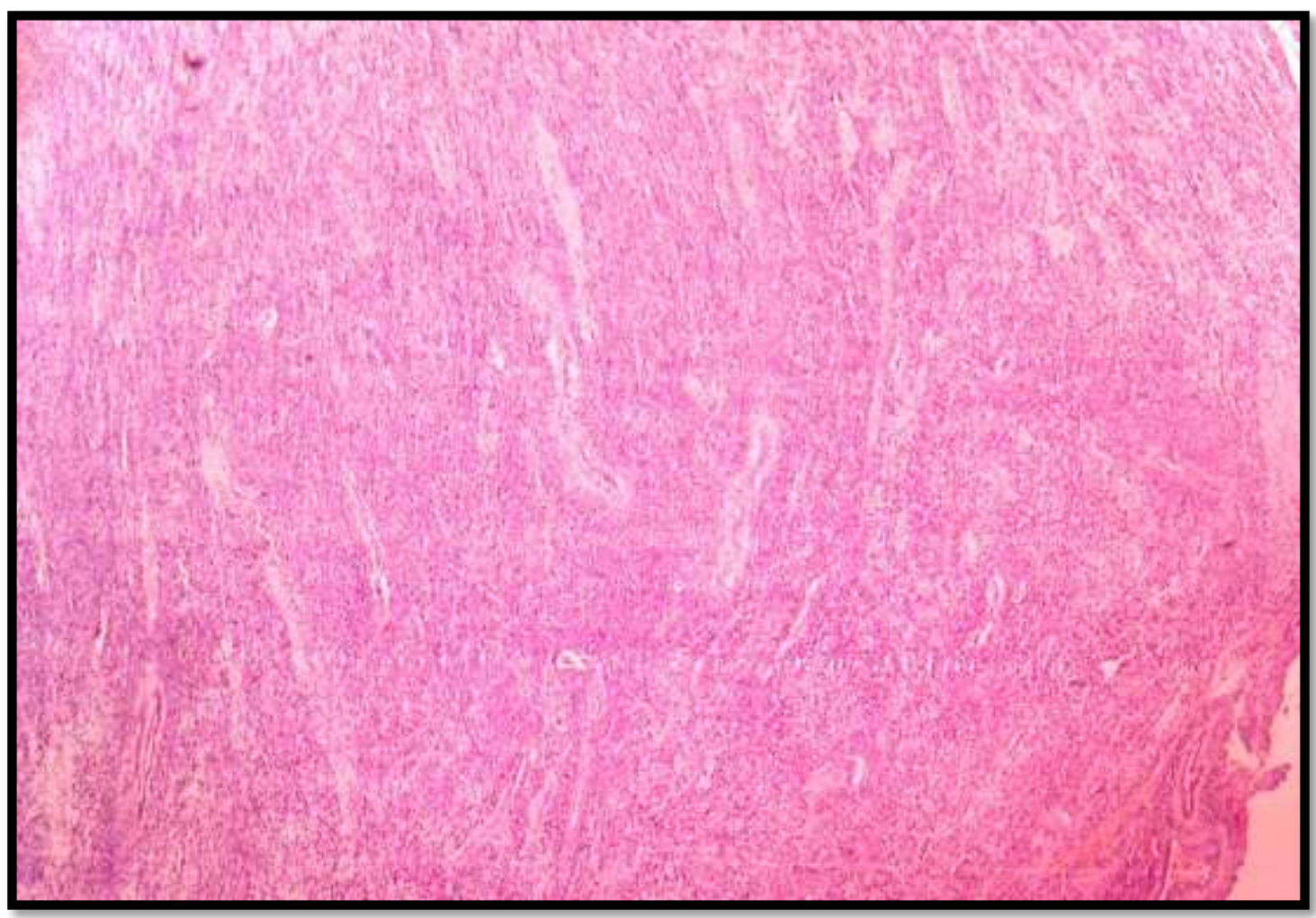

Fig 4:- Cellular leiomyoma- Low power view (100 X) showing cellular neoplasm composed of spindle cells.

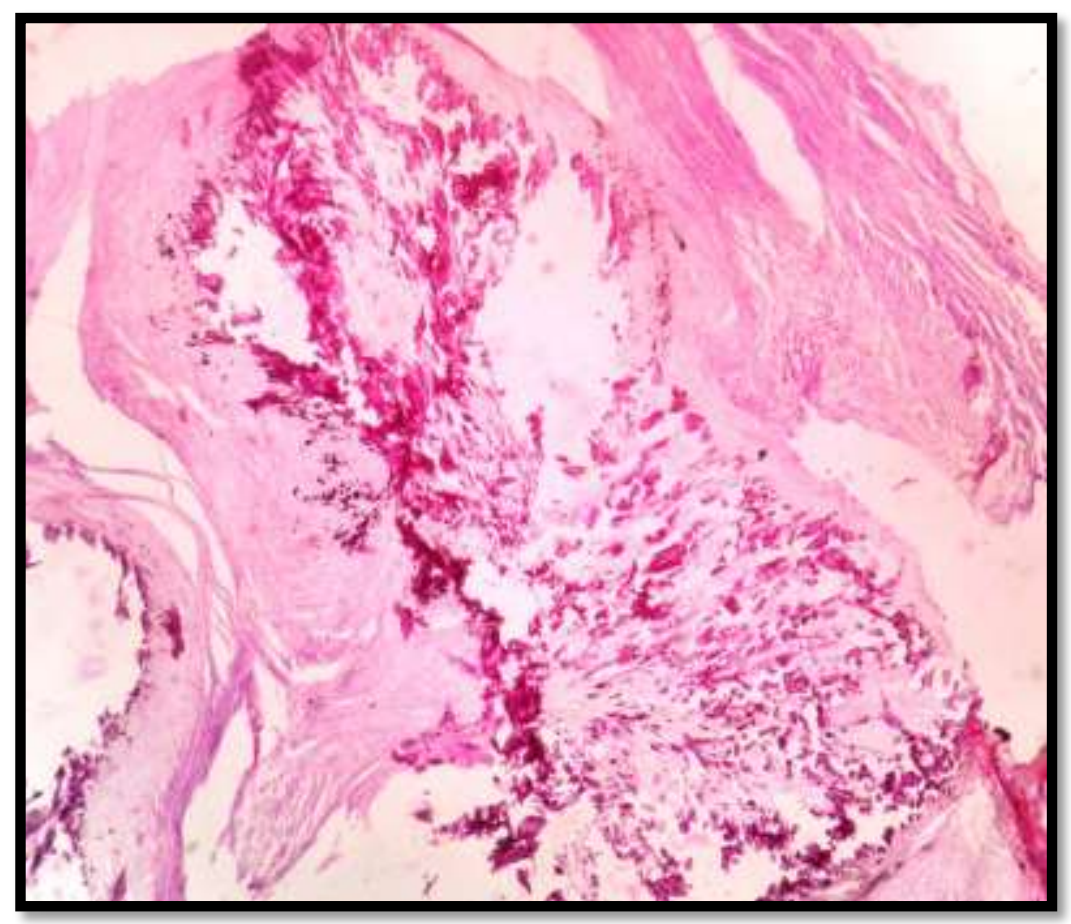

Fig5:-High power view (400 X) showing calcific degeneration of leiomyoma. 


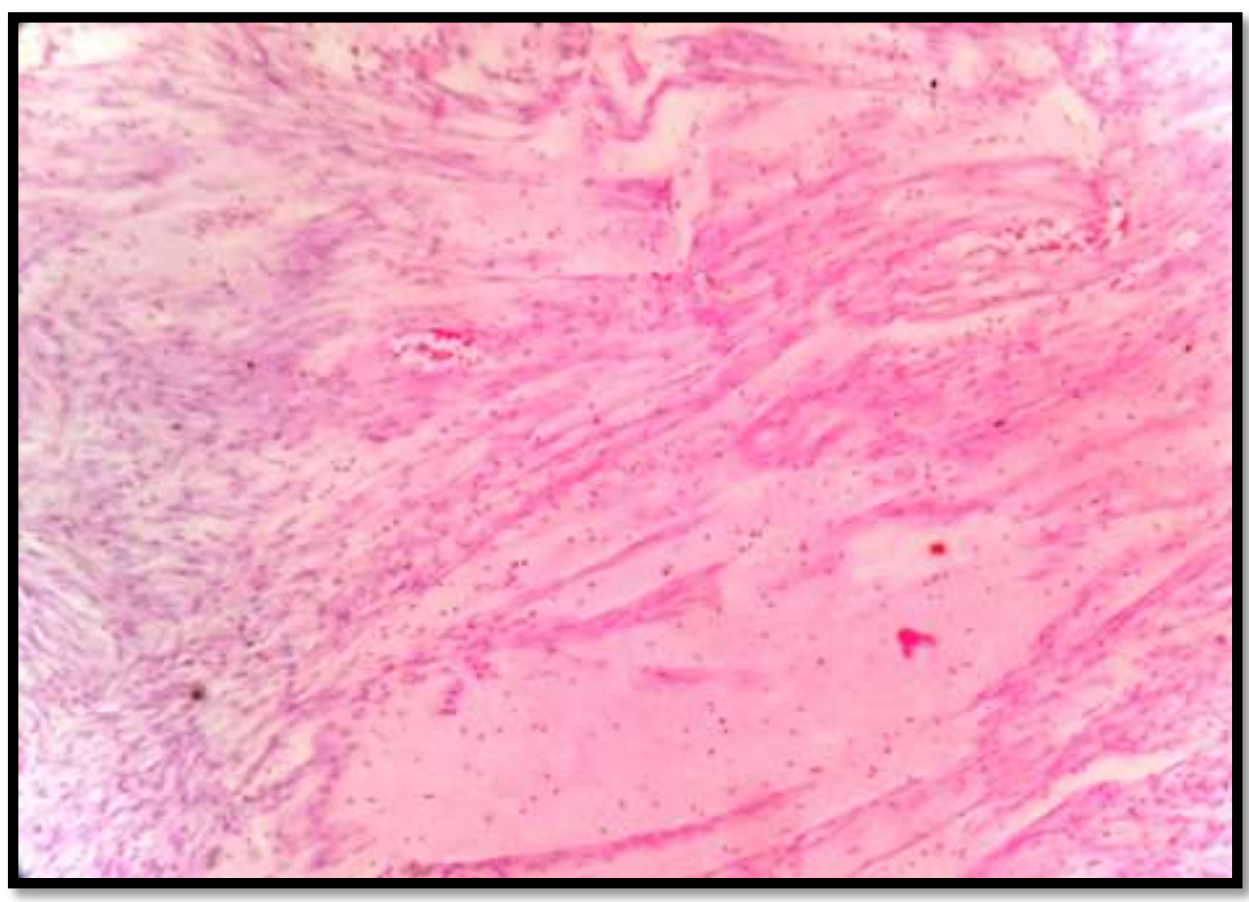

Fig6:- High power view (400 X) showing myxoid degeneration of leiomyoma.

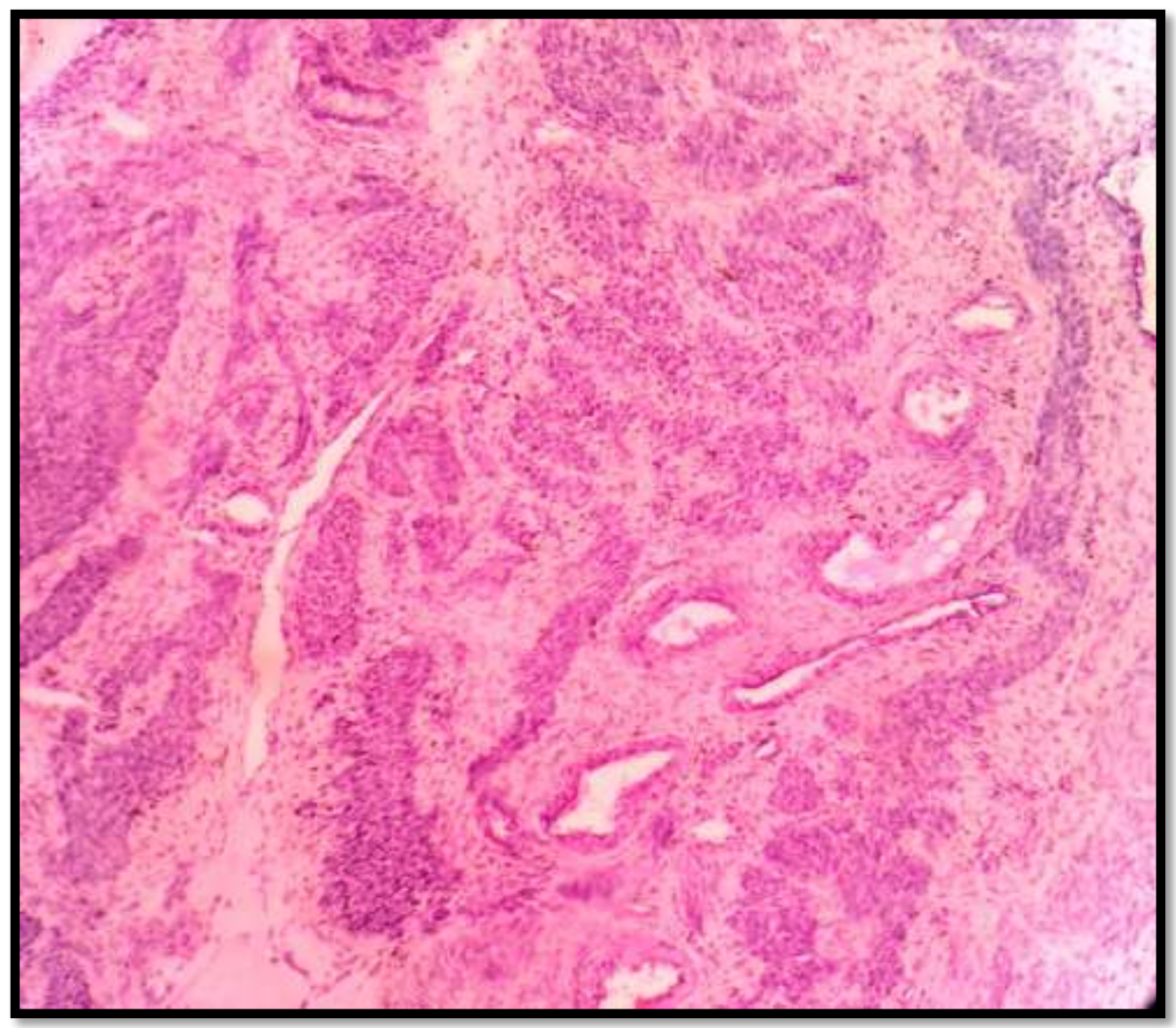

Fig7:- Low power view (100 X) showing hydropic degeneration of leiomyoma. 


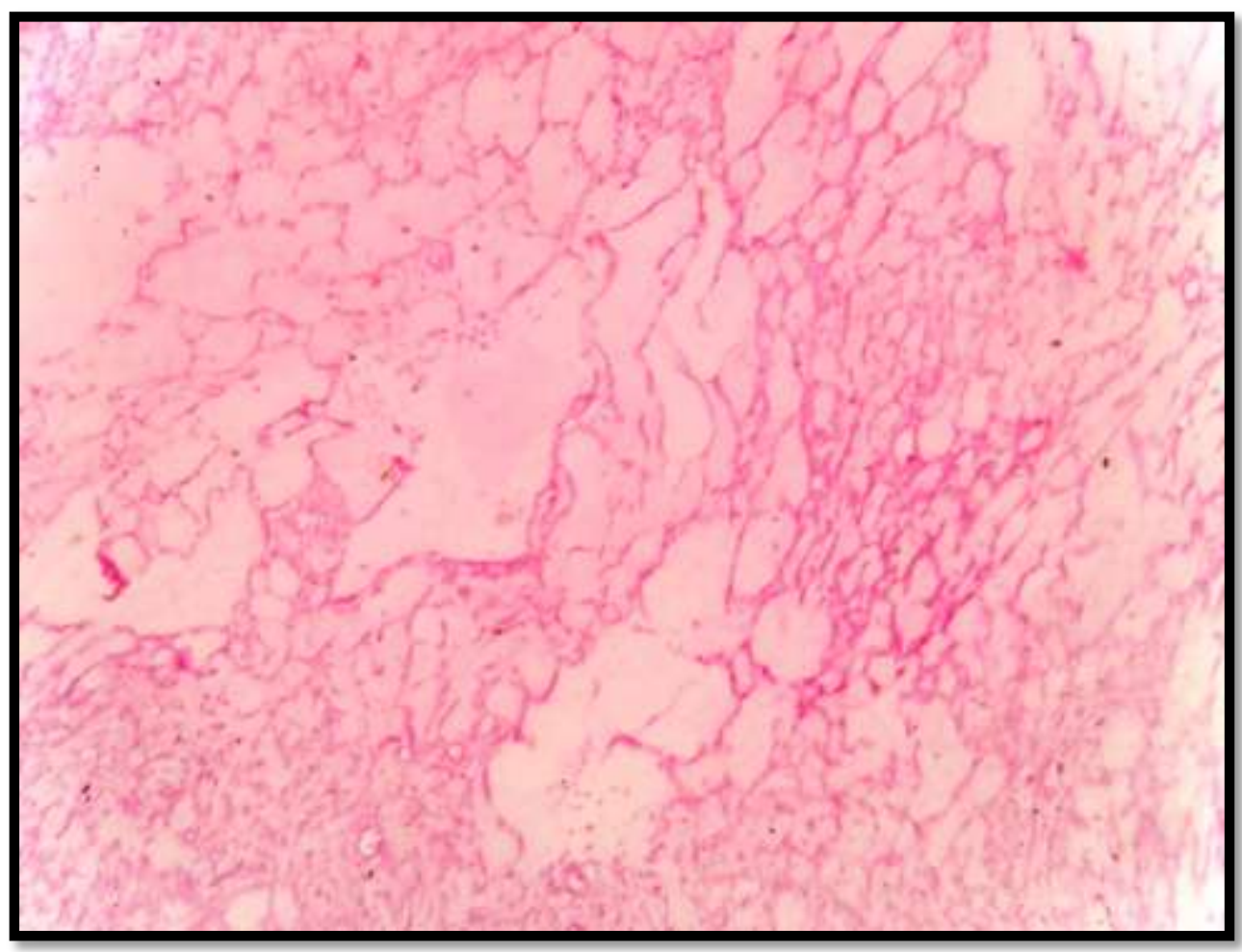

Fig8:- High power view (400 X) showing fatty degeneration of leiomyoma.

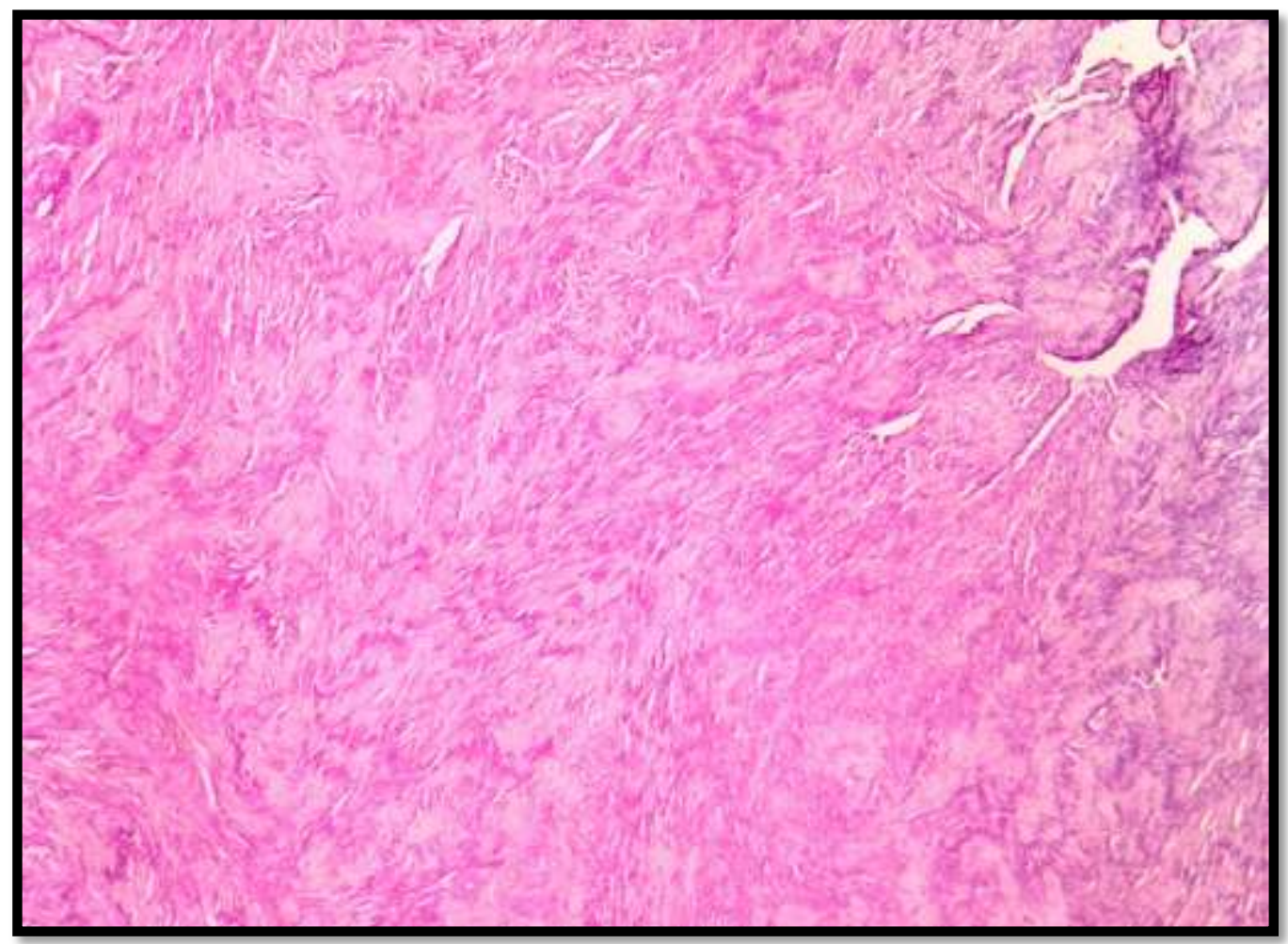

Fig9:- Low power view ( $100 \mathrm{X}$ ) showing neurilemmoma like variant of leiomyoma. 


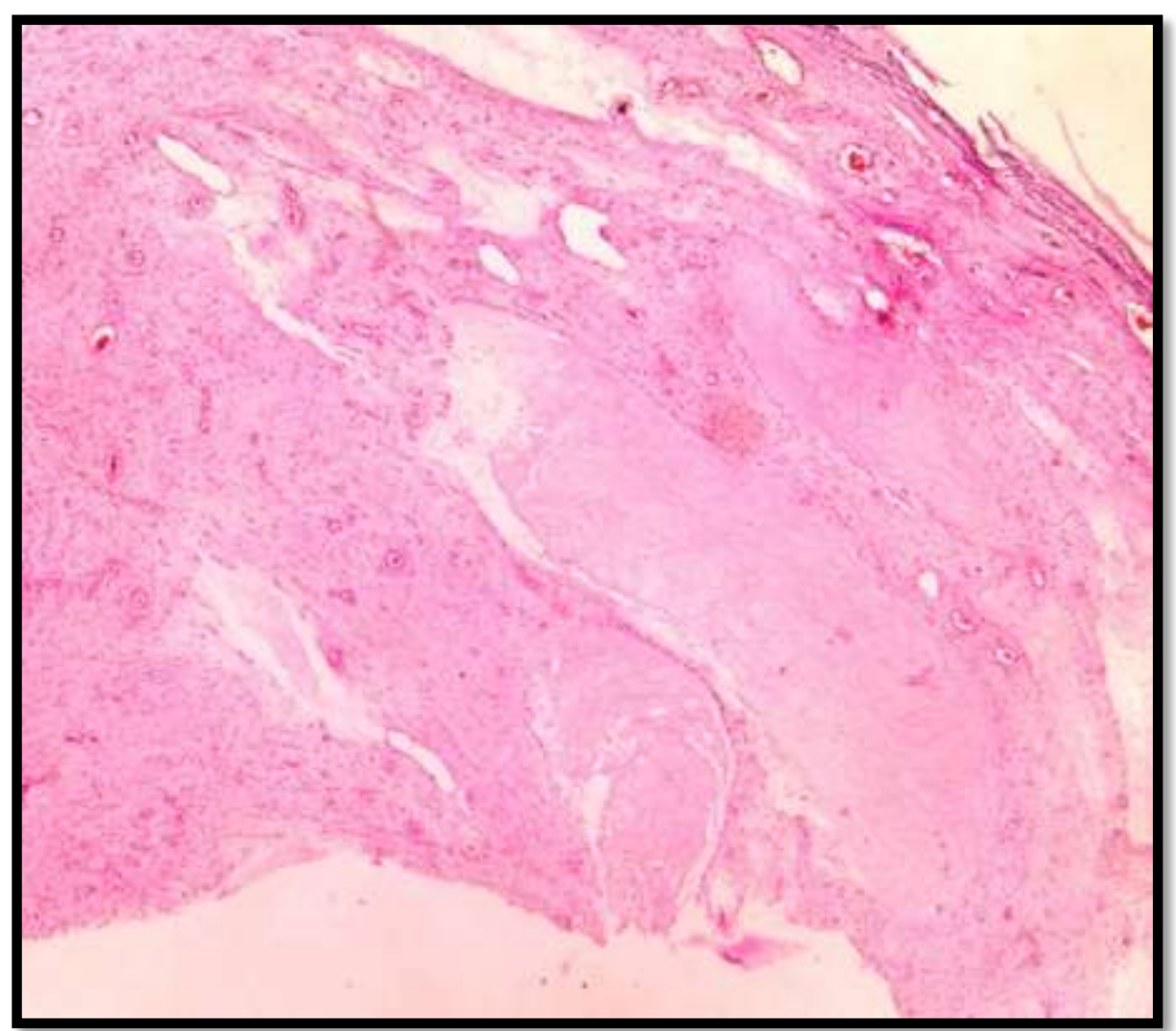

Fig10:- Low power view $(100 \mathrm{X})$ showing hyaline degeneration of leiomyoma.

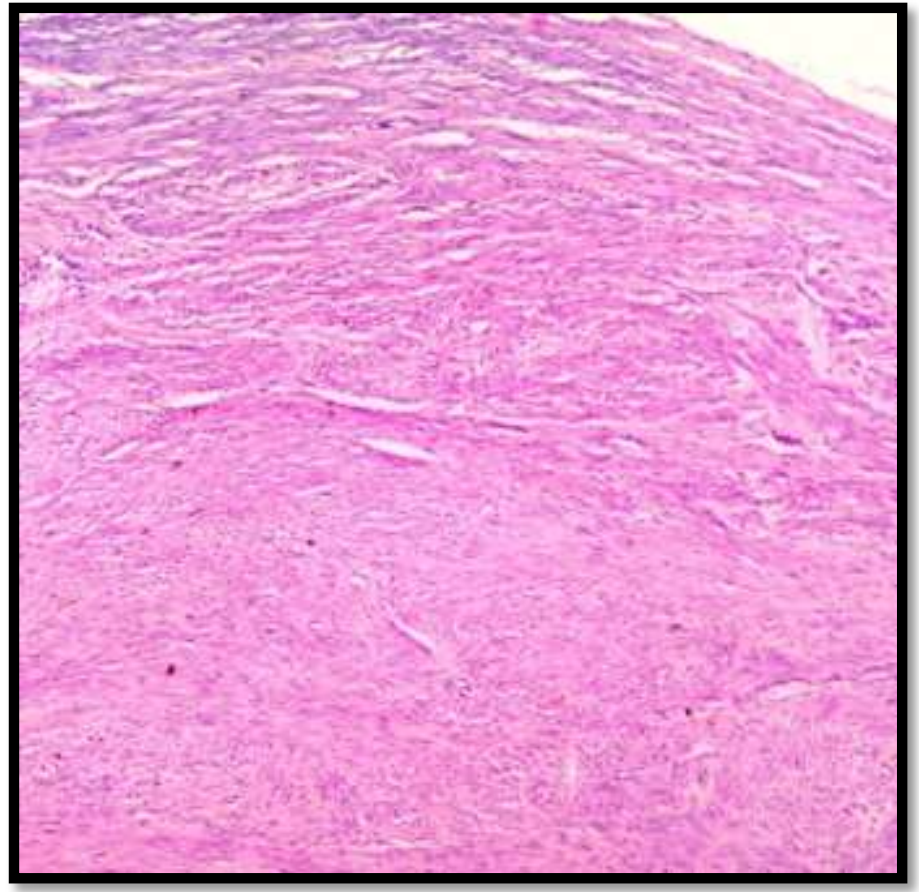

\section{Discussion:-}

Fig11:- Low power view (100 X) showing typical leiomyoma.

Leiomyoma was the most common uterine neoplasms.(6,7) Based on location,they have been classified as submucosal, intramural, subserosal leiomyoma. They were noted clinically in $20-30 \%$ of women over 30 years of age. $(8,9)$ Most leiomyomas were detected in middle aged women. 
In this study, the mean age of diagnosis was around 23-45 years. Most of the patients were asymptomatic and some had clinical presentation ranging from menorrhagia, pain abdomen, mass abdomen, dysmenorrheal and few presented with primary infertility, recurrent abortions. Four cases were found to be associated with pregnancy and these patients underwent myomectomy during their second trimester. Premenopausal patients with fibroid underwent hysterectomy.

The mean size of leiomyoma was between $1-15 \mathrm{~cm}$. Most specimens revealed characteristic macroscopic appearance. Typical leiomyomas constituted about $88.4 \%$ and variants constituted to about $11.6 \%$ which includes mitotically active leiomyoma, cellular leiomyoma, atypical/symplastic leiomyoma, leiomyoma with fatty degeneration, calcific degeneration, hydropic degeneration, hyaline degeneration, neurilemmoma like leiomyoma.

Most of these variants carry no clinical significance, yet their correct diagnosis and differentiation from malignant myometrial neoplasms were important because of their good prognosis.

In this study, variants of leiomyoma constituted about $11.6 \%$. Hyaline degeneration was the common finding and it was associated with large tumor size.

Other degenerative changes include red degeneration, calcific degeneration, fatty degeneration and hydropic degeneration.

\section{Mitotically active leiomyoma:-}

We reported three cases of mitotically active leiomyoma. All these cases were reported in premenopausal women and they found to have 6-9 mitosis/10 high power field. Thus, mitotically active leiomyomas usually have more than or equal to 5 mitotic figures per 10 high power field. ${ }_{(10,11,12,13)}$ It is imperative that this diagnosis not be used for neoplasms that exhibit moderate to severe nuclear atypia, for those that contain abnormal mitotic figure or for those that demonstrate zones of tumor cell necrosis.

\section{Cellular leiomyoma:-}

A cellular leiomyoma is one in which the cellularity is significantly greater than the surrounding myometrium. We reported three cases of cellular leiomyoma.

The isolated finding of hypercellularity may suggest a diagnosis of leiomyosarcoma, but cellular leiomyoma lacks tumor cell necrosis, has few mitotic figures and lacks the moderate to severe cytological atypia seen in leiomyosarcoma. A cellular leiomyoma composed of small cells with scant cytoplasm can be confused with an endometrial stromal tumor.

Features that help distinguish a cellular leiomyoma from a stromal tumor are the spindled shape of the cell, the fusiform shape of the nuclei, the reticulin pattern and absence of a plexiform vasculature.

Reticulin fibres tend to parallel the fascicles of cells in a leiomyoma, but reticulin network surrounds individual tumor cells in an endometrial stromal nodule.

Large thick walled muscular vessels serve to distinguish a cellular leiomyoma from an endometrial stromal

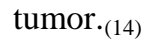

\section{Symplastic / atypical leiomyoma:-}

As an isolated finding, cytological atypia, even when severe, is an unreliable criterion for the diagnosis of clinically malignant uterine smooth muscle tumors because it can be seen in clinically benign otherwise banal smooth muscle neoplasm.(15)

We reported two cases of symplatic leiomyoma. Both the patients were in the premenopausal age group. Their clinical presentation was dysmenorrhea and menorrhagia. Gross examination of both the specimens revealed a well circumscribed grey white, firm, homogenous mass. There were no areas of necrosis, hemorrhage. Microscopic examination revealed a well circumscribed neoplasm arranged in fascicles and bundles composed of spindle shaped cells with moderate eosinophilic cytoplasm with pleomorphic hyperchromatic nuclei. Extensive sampling was done 
and it revealed mitosis less than five mitotic figures per 10 high power field. There were no areas of necrosis, hemorrhage or zone of tumor cell necrosis seen.

\section{Neurilemmoma like leiomyoma:-}

A case of neurilemmoma like leiomyoma was diagnosed in 37 year old female, who presented with excessive bleeding. The tumor was intramural in location, measured $4.5 \mathrm{~cm}$ in diameter. Histological examination showed fasicular pattern of leiomyoma with areas showing nuclear palisading mimicking a schwannoma (16).

\section{Outcome:-}

Most of the patients were followed up and their follow up period was uneventful.

\section{Conclusion:-}

Most subtypes of leiomyoma were chiefly of clinical interest in that they mimic malignancy in one or more respects. Though the frequency with which they occur remains less, their correct diagnosis was essential and they need to be differentiated from malignant myometrial neoplasms as most of these variants carry good prognosis and of less clinical significance.

\section{References:-}

1. Baird DD, Dunson DB, Hill MC, et al. High cumulative incidence of uterine leiomyoma in black and white women: ultrasound evidence. Am J Obstet Gynecol 2003; 188:100.

2. Buttram VC Jr, Reiter RC. Uterine leiomyomata: etiology, symptomatology, and management. Fertil Steril 1981; 36:433.

3. Serden SP, Brooks PG. Treatment of abnormal uterine bleeding with the gynecologic resectoscope. J Reprod Med 1991; 36:697.

4. Blaustein's pathology of the female genital tract- sixth edition.

5. Roth LM, Reed RJ, Sternberg WH, Cotyledonoid dissecting leiomyoma of the uterus the Sternberg tumor. Wilkinson N, Rollason TP (Eds).Am J Surg Pathol 1996:12):1455-61.

6. Payson M, Leppert P et al (2006) Epidemiology of myomas. Obstet Gynecol Clin N Am 33(1):1-11.

7. Vollenhoven B (1998) Introduction: the epidemiology of uterine leiomyomas. Baillie `res Clin Obstet Gynaecol 12(2):169-176.

8. Cramer SF, Patel A (1990) The frequency of uterine leiomyomas.Am J Clin Pathol 94:435-438.

9. Day Baird D, Dunson DB et al (2003) High cumulative incidence of uterine leiomyoma in black and white women: ultrasound evidence.Am J Obstet Gynecol 188(1):100-107.

10. Bell SW, Kempson RL et al (1994) Problematic uterine smooth muscle neoplasms: a clinicopathologic study of 213 cases. Am J Surg Pathol 18:535-558

11. Dgani R, Piura B et al (1998) Clinical-pathological study of uterine leiomyomas with high mitotic activity. Acta Obstet Gynecol Scand 77(1):74-77

12. O'Connor DM, Norris HJ (1990) Mitotically active leiomyomas of the uterus. Hum Pathol 21:223-227.

13. Perrone T, Dehner LP (1988) Prognostically favorable "mitotically active" smooth-muscle tumors of the uterus. A clinicopathologic study of ten cases. Am J Surg Pathol 12:1-8

14. Oliva E, Young RH et al (1995) Cellular benign mesenchymal tumors of the uterus: a comparative morphologic and immunohistochemical analysis of 33 highly cellular leiomyomas and six endometrial stromal nodules, two frequently confused tumors. AmJ Surg Pathol 19:757-768.

15. Downes KA, Hart WR (1997) Bizarre leiomyomas of the uterus: a comprehensive pathologic study of 24 cases with long-term follow-up. Am J Surg Pathol 21(11):1261-1270

16. Gisser SD, Young I (1977) Neurilemoma-like uterine myomas: an ultrastructural reaffirmation of their nonSchwannian nature.Am J Obstet Gynecol 129:389-392 